\title{
AS PRÁTICAS INVESTIGATIVAS E O DIÁRIO DE CAMPO NA FORMAÇÃO DO PEDAGOGO EM ESPAÇOS NÃO ESCOLARES
}

\author{
Cláudia Inês Horn ${ }^{1}$ \\ https://orcid.org/0000-0002-1612-2067 \\ Fabiane Olegário ${ }^{2}$ \\ http://orcid.org/0000-0001-6855-3064
}

\begin{abstract}
RESUMO: Este artigo objetiva apresentar algumas experiências realizadas nas disciplinas de Prática Investigativa I, II e III, que integram o currículo do Curso de Pedagogia da Universidade do Vale do Taquari Univates, localizada na cidade de Lajeado/RS/BRA. A partir da compreensão sobre espaços escolares e não escolares, são apresentados os movimentos de escolarização que podem ser mobilizados em ambos espaços, por meio de registros feitos pelos estudantes do referido Curso de Pedagogia em seus diários de campo, fruto do trabalho cartográfico desenvolvido nas disciplinas. Busca refletir sobre como as disciplinas de Práticas Investigativas interrogam o próprio currículo do Curso de Pedagogia e, sobretudo, como as experiências dos acadêmicos redigidas no Diário de Campo colabora para a formação do futuro pedagogo. É possível concluir que a atuação de pedagogos em espaços não escolares e o uso de diários de campo podem tensionar e mobilizar novos desafios à formação inicial.
\end{abstract}

PALAVRAS-CHAVE: Pedagogia; Práticas; Formação docente; Experiências.

\section{INVESTIGATIVE PRACTICES AND THE FIELD JOURNAL ON THE PEDAGOGUE'S FORMATION AT UNSCHOOLED PLACES}

ABSTRACT: This paper aims to present some experiences accomplished on Investigative Practices I, II and III subjects, whose compose the Pedagogy course curriculum at Universidade do Vale do Taquari Univates, located at Lajeado/RS/BRA. From the comprehension about schooled and unschooled places, It presents the schooling movements that can be mobilized at both places, by photographic registers done by students of the referred Pedagogy course, on their field journal, product of the Cartography work developed at class. It pursuits to think about how the Investigative

\footnotetext{
${ }^{1}$ Doutora em Educação - Universidade do Vale dos Sinos- UNISINOS. Docente do Centro de Ciências Humanas e Sociais- CCHS - Universidade do Vale do Taquari- Univates - Lajeado/RS/BRA. cihorn@univates.br ${ }^{2}$ Doutora em Educação - Universidade Federal do Rio Grande do Sul- UFRGS. Docente do Centro de Ciências Humanas e Sociais-CCHS - Universidade do Vale do Taquari- Univates-Lajeado/RS/BRA.fabiole@univates.br
} 
Practices subject questions the Pedagogy course curriculum and, above all, how the students experience ruled on the field journal cooperate to the future Pedagogue formation. It is possible to say that the presence of Pedagogues at unschooled places and the field journal can tensionate and mobilize new challenges to the beginning formation

KEYWORDS: Pedagogy; Practices; Teacher Education; Experiences.

\section{LAS PRÁCTICAS DE INVESTIGACIÓN Y EL DIARIO DE CAMPO EN LA FORMACIÓN DEL PEDAGOGO EN ESPACIOS NO ESCOLARES}

RESUMEN: Este trabajo tiene como objetivo presentar algunas experiencias llevadas a cabo en las asignaturas: Práctica de Investigación I, II y III; que integran el plan de estudios del Curso de Pedagogía en la Universidade do Vale do Taquari -Univates, ubicado en la ciudad de Lajeado/RS/BR. Tomando como punto de partida la comprensión de espacios escolares y no escolares, son presentados los movimientos de escolarización que pueden darse en ambos espacios; al mismo tiempo, son utilizados los registros realizados por los estudiantes en sus diarios de campo, fruto del trabajo cartográfico desarrollado en las materias de prácticas antes mencionadas. Busca reflexionar sobre cómo las disciplinas de Prácticas de Investigación interrogan el currículo del propio Curso de Pedagogía y, sobre todo, cómo las experiencias de los educandos plasmadas en sus Diários de Campo colaboran para la formación del futuro pedagogo. Es posible concluir que las prácticas de los pedagogos en espacios no escolares, así como el uso de diarios de campo pueden tensionar y movilizar nuevos desafíos para la formación inicial de los futuro profesionales.

PALABRAS-CLAVE: Pedagogía; Prácticas; Formación Docente; Experiencias

\section{Introdução}

O presente artigo constitui-se em investimentos preliminares de uma investigação desenvolvida no Curso de Pedagogia da Universidade do Vale do Taquari Univates - Lajeado/Brasil, quando o referido Curso é convocado a reestruturar seu Plano de Curso e sua matriz curricular e repensar as práticas de ensino, assim como o currículo e a formação do futuro pedagogo. Nessa investigação, não pretendemos responder por que a Resolução CNE/CP № 01/2006, que institui as Diretrizes Curriculares Nacionais para o Curso de Graduação em Pedagogia, bem como a Resolução CNE/CP № 02/2015, que institui Diretrizes Curriculares Nacionais para a formação inicial em nível superior 
(cursos de licenciatura, cursos de formação pedagógica para graduados e cursos de segunda licenciatura) e para a formação continuada, ampliam o campo de atuação da Pedagogia para além dos espaços escolares. Tampouco queremos interrogar o que a legislação procura com isso e qual é a sua estratégia global. Antes, pretendemos pensar para o que, efetivamente, as disciplinas de Práticas Investigativas, assim como a escrita dos diários de campo, contribuem na formação dos alunos do Curso de Pedagogia

Em outras palavras, ao invés de perguntarmos como os espaços não escolares ganham visibilidade na formação do pedagogo, pretendemos compreender como os saberes vêm sendo progressivamente constituídos a partir da inserção, da intervenção e da realização das práticas dos alunos do Curso de Pedagogia da Universidade do Vale do Taquari Univates em espaços não escolares, especialmente por meio das disciplinas de Práticas Investigativas I, II e III e da escrita em diários de campo. Mesmo sabendo que cada disciplina apresenta as suas especificidades, há o objetivo comum de ampliar o campo de formação e atuação do futuro pedagogo, pois, conforme o Projeto Pedagógico do Curso de Pedagogia da Univates (2017, p.22), "a formação e atuação do pedagogo como docente, pesquisador e gestor em espaços formais e não formais é construída com base nas relações sociais, na articulação entre saberes, nos valores éticos e estéticos e na socialização dos conhecimentos".

A partir da escrita deste artigo, além de compartilhar as experiências vivenciadas pelos alunos, intencionamos compreender como as disciplinas de Práticas Investigativas contribuem na formação inicial do pedagogo por meio da escrita no Diário de Campo. Para tanto, na primeira seção, discorremos sobre os espaços escolares e não escolares, a fim de problematizar os movimentos de escolarização que neles emergem. Na segunda seção, apresentamos, em linhas gerais, o foco de cada uma das disciplinas de Práticas Investigativas do Curso de Pedagogia, buscando refletir como elas interrogam o próprio currículo desse Curso e, sobretudo, como as experiências de escritas dos acadêmicos colaboram para a formação do pedagogo. Além disso, discutimos a proposta de escrita cartográfica, a qual perpassa as três disciplinas, e apresentamos trechos escritos pelos próprios acadêmicos do Curso nos Diários de campo. Ao final, argumentamos em favor da atuação de pedagogos em espaços não escolares, atuação esta que tensiona de forma constante os movimentos de escolarização que mobilizamos com as práticas pedagógicas; sobretudo, buscamos levantar questões que ajudem a criar outras possibilidades para seguirmos pensando a inserção do pedagogo nesses espaços. 
Espaços não escolares, movimentos não escolarizados e práticas investigativas

Como referimos anteriormente, as modificações sugeridas pela Resolução CNE/CP № 01/2006 (Diretrizes Curriculares Nacionais para o Curso de Graduação em Pedagogia) e pela Resolução CNE/CP № 02/2015 (Diretrizes Curriculares Nacionais para a formação inicial em nível superior) objetivam interrogar os currículos dos Cursos de Pedagogia, ocasionando suas reformulações e adequações. Como aponta o artigo 13 da Resolução CNE/ CP № 02/2015, os cursos de licenciatura, considerando-se a complexidade e a multirreferencialidade dos estudos que englobam, deverão incluir "o ensino e a gestão educacional, e os processos educativos escolares e não escolares" (BRASIL, 2015, p. 11).

Tendo tal legislação como norte para a formação do pedagogo na contemporaneidade, nos valemos dos estudos de Gohn (2010) sobre educação formal, não formal e informal, a fim de compreender as especificidades de cada uma delas. Segundo Gohn (2010, p.15), "articular a educação, em seu sentido mais amplo, com os processos de formação dos indivíduos como cidadãos, ou articular a escola com a comunidade educativa de um território [...] é uma urgência e uma demanda da sociedade atual". É por tal motivo que emerge a construção de um olhar ampliado acerca do papel do pedagogo no contexto em que estamos inseridos. De acordo com Gohn (2010), há distinções entre a educação formal, não formal e informal, embora muitos autores considerem que a educação não formal teria o mesmo sentido de educação informal. Educação formal, para a autora, é aquela desenvolvida no espaço escolar com conteúdos previamente demarcados; pressupõe regras e normas a partir de uma legislação vigente, em que o educador é o professor. Já a educação não formal é aquela que se aprende no mundo da vida, na medida em que o sujeito compartilha experiências em espaços de ações coletivas onde a aprendizagem é gerada; há intencionalidade, ou seja, um objetivo comum referente a um determinado grupo. Por exemplo: movimentos sociais que abrangem grupos distintos, cujo objetivo, geralmente, é proporcionar o reconhecimento e o acesso aos direitos civis. A educação informal tem como característica fundamental a socialização do indivíduo em grupos coletivos, tais como: família, escola, religião, clube, ou seja, opera em ambientes espontâneos, onde o processo de aprendizagem é constituído no processo de vivência dos sujeitos (GOHN, 2010).

Tais movimentos nos fazem perceber a importância do debate acerca destes três conceitos - não formal, informal e formal. Partimos desse 
debate a fim de ampliarmos o entendimento sobre a formação do Pedagogo na atualidade. Nesse sentido, o Curso de Pedagogia da Univates apresenta três disciplinas que objetivam conhecer e experimentar outros espaços de atuação do pedagogo, além do ambiente escolar. São elas: a) Prática Investigativa I, cuja ementa problematiza os discursos que constituem a pobreza, a infância e a educação em espaços não escolares; b) Prática Investigativa II, que propõe conhecer espaços não escolares da região do Vale do Taquari por meio de pesquisa de campo, a fim de perceber que a atuação do pedagogo na contemporaneidade está além do espaço escolar. Para tal pesquisa, os acadêmicos utilizam o método da cartografia; c) Prática Investigativa III, que indica o estudo e as implicações das organizações não governamentais (ONGs) na educação ambiental, com vistas à criação de uma proposta pedagógica em um espaço não escolar. Essas disciplinas integram o currículo pelo fato de a legislação ampliar as possibilidades de atuação do pedagogo, indo além da educação básica no espaço escolar.

Antes de questionar a própria legislação e suas propostas de modificação, queremos discutir como compreendemos os espaços não escolares e os movimentos de escolarização que lá podem ser mobilizados mediante as práticas pedagógicas. Nessa perspectiva, as expressões "espaços escolares e não escolares" e "movimentos escolarizados e não escolarizados" serão utilizadas neste artigo, bem como nos estudos das referidas disciplinas de Práticas Investigativas.

Consideramos importante realizar tal debate, uma vez que, tanto em espaços escolares quanto não escolares, vemos emergir movimentos de escolarização. Escolarização aqui é compreendida como um movimento capaz de:

[...] inventar espaços próprios para a educação, controlar o tempo em que se desenvolvem as atividades, selecionar saberes aos quais se confere caráter de universalidade, inventar uma relação saber-capacidade, obrigar à frequência, desqualificar outras práticas em educação, seriar, avaliar e certificar (CORRÊA, 2000, p.54).

Assim, quando nos referimos às instituições escolares e às suas propostas pedagógicas, geralmente colamos o conceito de escolarização, tomando as duas palavras como sinônimas. Isso significa dizer que um currículo acionado pelos espaços escolares engloba sempre processos de escolarização e que, por sua vez, um currículo em espaços não escolares não seria escolarizante. Será que essa relação pode ser tomada como natural e binária? Corrêa e Preve 
(2011) ajudam-nos a pensar sobre educação e escolarização:

Educação é qualquer movimento que produz uma modificação. Um movimento do pensamento, um movimento do corpo, um movimento no espaço, qualquer coisa que produza variação em termos de compreensão ou de perspectiva ou de visão. A educação, assim, não conduz necessariamente ao bem, à felicidade ou ainda a um ideal de humano e de sociedade. Educação e processos educacionais não são bons. E não são maus. São processos de modificação (CORRÊA; PREVE, 2011, p. 187).

Percebe-se que a educação pode habitar espaços escolares e não escolares. Já a escolarização envolve espaços e tempos projetados para os processos de ensino e aprendizagem, contemplando currículos planejados e prescritos a partir de uma listagem de objetivos, conteúdos, competências e habilidades, além de uma sequência gradativa de aulas, atrelada à prática de avaliação contínua, entre outros aspectos. Crizel e Hattge (2015) apontam que o espaço escolar se refere "às instituições formais de educação que são dirigidas e organizadas a partir de diretrizes nacionais; já os espaços não escolares compreendem outras organizações que não possuem objetivos formais de ensino podendo este acontecer na rua, em ONGs, projetos sociais, teatros, museus, entre outros. Já os movimentos compreendem os modos de ocupar os espaços" (CRIZEL; HATTGE, 2015, p. 213).

Cabe mencionar que as práticas escolarizadas são planejadas em consonância com o sistema de ensino, que visa a incluir a todos, utilizando estratégias específicas que, de certo modo, estão calcadas na Legislação referente à educação. Assim, a instituição escolar ocupa uma posição de excelência voltada aos processos escolarizados, os quais objetivam efeitos escolarizantes nos sujeitos que a frequentam. O currículo é pensado a partir de conteúdos, que precisam ser aprendidos pelos estudantes com rapidez, servindo como base para a avaliação do aluno e da sua produtividade (MUNHOZ, 2012). Poderíamos, então, pensar que a escola é, por excelência, um espaço escolarizante.

Nos espaços não escolares, a educação também pode acontecer, pois eles são potencializadores de aprendizagens, vivências e experiências (MUNHOZ, 2012). Somos provocadas a pensar que os processos de educação ocorrem em espaços não escolares, mas que os processos de escolarização também podem aí acontecer. Desse modo, a instituição escolar não pode carregar o fardo único da escolarização, uma vez que, dependendo das práticas, os espaços não escolares podem desencadear processos de escolarização e 
produzir efeitos escolarizantes, de acordo com a forma que estão organizados, visto que:

Os movimentos não escolarizados são entendidos como aqueles outros modos de ocupar os espaços que possibilitam relações diferentes com o tempo e os sujeitos envolvidos, criando outros agenciamentos e composições. Mas é importante destacar que ambos movimentos podem acontecer tanto em espaços escolares quanto não escolares simultaneamente porque um é atravessado e constituído pelo outro constantemente (CRIZEL; HATTGE, 2015, p. 213).

O que nos toca aqui é pensar como os movimentos não escolarizados realizados pelos alunos do Curso de Pedagogia numa determinada Instituição Escolar considerada como espaço formal de educação interferem na formação inicial, visto que a prática proposta por meio de oficinas objetiva não corresponder às atividades escolares. Corrêa e Preve (2011) compartilham a experiência das oficinas como forma de escapar da escolarização e afirmam que "não produzir efeitos escolarizantes é abrir espaço para o desconhecido, reduzir o investimento na segurança do mesmo, não cultivar esperanças que fazem esperar e que consolam" (CORRÊA; PREVE, 2011, p. 197).

Nesse sentido, entendemos que a formação do futuro pedagogo na contemporaneidade abrange uma gama de possibilidades de atuação, tanto em espaços escolares quanto em espaços não escolares, sendo entremeada por movimentos não escolarizados e escolarizados. Importante destacar que, independentemente dos movimentos que instituem os espaços, o pedagogo não deixa de ser atravessado pelas relações de poder, saber e verdade, as quais o convocam a pensar de outros modos os espaços - escolares e não escolares - e os movimentos escolarizados e não escolarizados.

\section{As práticas investigativas e o diário de campo}

Nesta seção, apresentamos ao leitor os objetivos de aprendizagem das disciplinas Prática Investigativa I, II e III do Curso de Pedagogia da Universidade do Vale do Taquari - Univates, assim como as propostas pedagógicas desenvolvidas em cada uma delas. Em meio a isso, optamos por mostrar excertos de diários de campo de quatro estudantes que se utilizaram da escrita cartográfica para registrar as sensações e as problematizações provocadas pelos encontros com as matérias de estudo. O Diário de Campo é compreendido como um procedimento produtor de novos questionamentos 
das possibilidades de atuação do pedagogo em espaços não escolares.

A disciplina Prática Investigativa I ocorre no segundo semestre acadêmico do Curso de Pedagogia e tem como objetivo central problematizar os discursos sobre pobreza, infância e família, assim como questões socioculturais, e percebê-los como uma produção social e histórica. A disciplina possibilita aos alunos a prática de movimentos não escolarizados em uma Instituição Escolar da rede pública. Problematizar discursos arraigados na sociedade certamente é uma tarefa nada fácil, visto que é necessário um conjunto de estratégias que possam nos sinalizar a importância de suspender tais discursos. Assim, conhecemos primeiramente o espaço institucional e o contexto escolar. Concomitantemente a essa atividade, seguem as aulas semanais na Universidade. Para que se possa discutir a educação não formal, é necessário fazer o exercício de deslocamento que permite diferenciá-la da escolarização, bem como assinalar as distinções entre a educação e os movimentos escolarizados, conforme tentamos debater na seção anterior.

Na Prática Investigativa I, os acadêmicos, juntamente com a equipe gestora e a equipe docente da Escola, convidam as crianças dos anos iniciais do Ensino Fundamental a participarem das oficinas que serão propostas aos sábados pela manhã na própria Escola. As práticas são realizadas em escolas da rede pública localizadas em bairros periféricos da cidade. Geralmente, esses bairros são apresentados pelos discursos como perigosos, violentos; devido a isso, haveria alto índice de vulnerabilidade social, gerando um número significativo de crianças com dificuldade de aprendizagem. A partir do conceito de discurso, problematizamos com os alunos as práticas discursivas concernentes à criança pobre e a estreita relação com as dificuldades em aprender o conteúdo formal escolar.

Aqui, interessa dizer que teorizamos a noção de discurso de Michel Foucault, que afirma que "em toda sociedade a produção do discurso é ao mesmo tempo controlada, selecionada, organizada e redistribuída por certo número de procedimentos que têm por função conjurar seus poderes e perigos, dominar seu acontecimento aleatório, esquivar sua pesada e temível materialidade" (FOUCAULT, 2009 p.8-9). O filósofo francês ajuda-nos a tensionar as práticas discursivas ao afirmar que se sabe "bem que não se tem o direito de dizer tudo, que não se pode falar de tudo em qualquer circunstância, que qualquer um, enfim, não pode falar de qualquer coisa" (FOUCAULT, 2009 p.8-9).

As oficinas são planejadas pelos acadêmicos com a intenção de escapar dos processos de escolarização, a fim de produzir outra relação entre aprender e ensinar. Cada encontro gera determinadas expectativas em relação 
ao que se passou na oficina e ao que se passará com aquilo que foi planejado, arquitetado, ensaiado, desejado para o momento de estar juntos. Não há obrigatoriedades, e a relação que se estabelece é de outra ordem, distante do que convencionalmente nomeamos como professor e como aluno. Abaixo, podemos notar que as expectativas - registradas por uma acadêmica em seu Diário de Campo - que antecederam as oficinas, incluindo o relato posterior à atividade, demonstram um processo reflexivo atrelado à amplitude do papel do pedagogo, para muito além do já sabido.

Num dia como hoje, o sol pairava sob a janela do ônibus, pela qual eu observava atentamente o caminho percorrido até chegar à Escola de aplicação, longe do centro da cidade. Foram tantas expectativas criadas a partir de comentários preconceituosos de pessoas alheias ao curso que ao entrar em contato com a Escola foram quebrados. O que nós poderíamos esperar dos encontros com as crianças no sábado pela manhã? O que eu posso dizer é que foram encontros inesquecíveis, não foram perfeitos, o que importa é que eu pude aprender com as crianças e me desafiar enquanto pedagoga inserida em um espaço escolar, mas com a prática não escolarizada (Diário de Campo, Prática Investigativa I, Camila, 2019/A).

Em relação à Prática Investigativa II, os espaços não escolares próximos à Univates são conhecidos e analisados. ONGs, hospitais, lares de idosos, Associação de Pessoas com Câncer e com Deficiência Física, Associação de Pais e Amigos dos Excepcionais, ecoterapia, abrigo para moradores de rua, centro terapêutico, Associação de Surdos, presídio, Instituto do Câncer Infantil, clube de mães, Centro de Referência Psicossocial Infantil, Centro de Referência Álcool e Drogas, abrigo para mulheres que sofreram violência doméstica, museus da cidade, Projeto Vida (acolhe crianças no turno inverso ao da escola), escolinhas de futebol e escolas de música são algumas possibilidades de espaços não escolares.

A proposta de investigação consiste em escolher um espaço dentro das possibilidades que há na região e observar os seguintes aspectos: procurar conhecer a história e objetivos da Instituição, o que é aprendido nesse espaço e como ocorrem a aprendizagem e as práticas de ensino. Além disso, indaga-se o papel do pedagogo nesses espaços não escolares. De acordo com o Diário de Campo de uma aluna do Curso de Pedagogia: 
As Práticas I e II fazem parte da minha vida porque me permitem a experimentação e a problematizar discursos e práticas instituídas pela sociedade. Mas, com o passar dos dias, a ansiedade e o medo foram sendo amenizados, e o mais importante é que, depois de tantos momentos de experiência com as crianças, eu não queria mais deixá-las, e foi aí que eu me questionei: por que ainda usamos as viseiras do preconceito? Quem as coloca em nós e por que deixamos? (Diário de Campo, Miriane, 2019/A).

A partir deste relato, compreendemos que é fundamental, para a formação do pedagogo, a possibilidade de vivenciar outras experiências, capazes de transformar sua maneira de olhar o mundo e, sobretudo, desconfiar da recorrência de alguns discursos postos como verdades. Por experiência, entendemos, a partir dos estudos de Larrosa (2014) aquilo que nos toca, que nos passa, que nos acontece e que, de fato, nos transforma. Portanto, a experiência exige do sujeito recepção, abertura e disponibilidade para que algo o toque. Na experiência, somos afetados e impelidos a mudar a forma de relacionarmo-nos com os outros, e isso não se alcança sem a presença de perguntas, problematizações e tensionamentos das verdades que nos constituem. Trata-se, portanto, de uma espécie de revisão do nosso próprio pensamento.

Encontramos no Diário de Campo a escrita cartográfica do aluno Mateus sobre a visita ao Instituto do Câncer Infantil, localizado em Porto Alegre, com o objetivo de conhecer o papel do pedagogo no espaço hospitalar.

Toda vez que olhamos uma criança em um estado de sofrimento, nos sensibilizamos. As crianças têm enorme poder de nos sensibilizar. Porém, não nos sensibilizamos pelo sofrimento delas, mas sofremos por vê-las. Não sentimos a sua dor e não sentimos a sua tristeza, mas as percebemos. Nosso olhar de adultos deforma muitas vezes a realidade. Não somos capazes de compreender o mundo como uma criança o compreende, e muito menos de interpretá-lo. Ora, o que isso tem a ver com a nossa visita? Por mais que admire e ache necessário aquele espaço no interior de um hospital, é um espaço pensado pelo adulto, e não pelas crianças. Antes de pacientes de um hospital, o Instituto do Câncer Infantil é ocupado por crianças. (Diário de Campo, Mateus, Prática Investigativa II, 2019/B)

Já na disciplina de Prática Investigativa III, os acadêmicos são desafiados a propor uma prática educativa não formal em um espaço não escolar, a qual implicará o movimento das três ecosofias. Nessa disciplina, elegemos como obra de referência As três ecologias, de Félix Guattari (2012, p.55), 
pois compreendemos a importância da discussão realizada neste livro, o qual nos instiga a pensar nas relações sociais (ecologia social), no meio ambiente (ecologia ambiental) e na produção da subjetividade humana (ecologia mental) como uma "disciplina comum ético-estética e, ao mesmo tempo, como distintas uma das outras do ponto de vista das práticas que as caracterizam". As ecologias articuladas à perspectiva ético-política são nomeadas pelo autor como ecosofia. Uma prática guiada pela ecosofia é capaz de ressingularizar o sujeito. Em outras palavras, a ecosofia desencadeia um processo modificador no modo de compreender o mundo e, sobretudo, de relacionar-se com o planeta.

A proposta de escrita apresentada aos alunos nas três disciplinas é a construção de ensaios cartográficos. Tomamos a escrita cartográfica como aquela que está sempre atenta aos cruzamentos gerados pelos encontros com os signos, que se apoderam do pensamento, impondo novas problemáticas. Trata-se de ser interpelado por inúmeras inquietudes que os alunos puderam registrar no Diário de Campo. "Esta forma de anotação escrita é pensada a partir da noção do dispositivo, cujo movimento de escrever, ler e pensar possibilita acompanhar e acolher novos encontros tecidos na experiência, que vão dando o tom, o ritmo" (OLEGÁRIO, 2011, p.34) às novas formas de compreensão do mundo. De acordo com Kastrup, a cartografia busca "investigar um processo de produção. De saída, a ideia de desenvolver o método cartográfico para a utilização em pesquisas de campo no estudo da subjetividade se afasta do objetivo de definir um conjunto de regras abstratas para serem aplicadas. Não se busca estabelecer um caminho linear para atingir um fim" (KASTRUP, 2007. p. 15).

O verbete cartografar, no sentido dicionarizado, significa "um conjunto de operações científicas, técnicas e artísticas para a elaboração de cartas geográficas e mapas" (FERREIRA, 2004, p.41) - em outras palavras, o mapa como instrumento da representação de um todo estático. Na contramão do significado dado pelo dicionário, Rolnik (1989) aponta a cartografia como uma definição provisória, pois, ao mesmo tempo em que desmancha certos mundos, se abre para a formação de outros mundos, o que atiça a necessidade de perceber que o espaço não escolar é constituído de material movediço em que jamais se estará seguro e tranquilo. Portanto, é emergente o exercício de estar à espreita de tudo que se passa onde se está, tal como podemos perceber no depoimento de acadêmicas do Curso de Pedagogia:

Acredito que cartografar aquilo que nos move exige que as práticas sejam pensadas e repensadas constantemente, pois nenhum encontro é igual ao outro, assim como nenhuma criança é igual à outra. Precisamos estar abertos ao improviso, atentos ao 
desconhecido que bate à nossa porta (Diário de Campo, Prática Investigativa III, Leila, 2019/A).

Se a cartografia consiste em dar visibilidade a subjetividades, em capturar o movimento, posso constatar que não se constitui tarefa fácil. Confesso que alguns encontros não me afectaram, não que não houvesse nada que pudesse emergir, mas talvez porque de minha parte não havia disponibilidade, talvez meus sentidos não estivessem aguçados o suficiente para capturar as intensidades, talvez naqueles momentos não houvesse a postura de um cartógrafo (Diário de Campo, Prática Investigativa III, Camila, 2019/A).

Ao cartografar os diferentes espaços não escolares, tomamos o Diário de Campo como um instrumento que aponta para outras direções ainda não pensadas, a partir dos efeitos produzidos pelos encontros, acentuando problemas que instigam a produção do trabalho investigativo, que está em vias de construção.

O Diário de Campo opera, segundo Bocco (2009, p.67), "como um dispositivo que gera saberes e realidades mais do que descreve". O registro do Diário de Campo é produzido individualmente, e a proposta é que os alunos possam ensaiar na escrita; "por esse motivo, é um registro que traz a intensidade do acontecimento, captando os elementos da cotidianidade enquanto estes criam novas configurações" (BOCCO, 2009, p.66). Tomando a ideia do Diário de Campo como indissociável do processo cartográfico, cada acadêmico é instigado a realizar seus ensaios de escritas. Aqui, interessa-nos um Diário de Campo que não descreve a realidade e os fatos observáveis, mas que potencializa tal realidade escolar como movente, arenosa, em constante metamorfose, o que justifica uma escrita que abandona a "técnica de relatório, pois não se trata de coletar dados, já que estes nunca existem como objetos esperando serem descobertos" (BOCCO, 2009, p.66).

Os acadêmicos do Curso de Pedagogia, ao concluírem as disciplinas Práticas Investigativas I, II e III, além de perceberem a atuação e a complexidade do papel do pedagogo na sociedade, são instigados a produzir textos que diferem da escrita acadêmica formal. De todo modo, é possível dizer que: as práticas investigativas comprometem o modo de habitar os espaços escolares e não escolares, na medida em que suspendem as certezas que os constituem, assim como convocam a problematizar os movimentos escolarizados e não escolarizados, ao passo que esses movimentos são, por natureza, formadores de subjetividades, ou seja, produzem formas de pensar e de sentir. Em meio 
a essas questões, a escrita cartográfica experimentada pelos estudantes compreende a invenção de novos processos de resistência às formas e aos discursos dominantes concernentes à educação, pois atende a um único objetivo: cartografar espaços e movimentos ainda por vir.

\section{Considerações finais}

Procuramos apresentar até aqui como as disciplinas de Práticas Investigativas estão movimentando o currículo do Curso de Pedagogia da Univates. Além delas, a disciplina Práticas Pedagógicas em Espaços Não Escolares (Estágio Supervisionado) também foi inserida na grade curricular do Curso, buscando parceria para o desenvolvimento das práticas pedagógicas no Presídio Estadual de Lajeado, na Instituição de Idosos - Vovolar, no Lar da Menina, na Clínica Universitária Regional de Educação e Saúde vinculada à Universidade do Vale do Taquari - Univates e no Centro de Atenção Psicossocial Infanto-Juvenil.

Nossa intenção, como professoras formadoras de futuros pedagogos, é pensar sobre a atuação do pedagogo em outros espaços institucionais, além do contexto escolar. Trata-se de problematizar tal atuação, rompendo com a lógica da reprodução dos processos de escolarização já cristalizados nas escolas. Interessante pensar que, ao debatermos sobre os movimentos escolarizantes em espaços não escolares, acabamos por desnaturalizar, cada vez mais, os processos de escolarização que parecem estar arraigados nas escolas do nosso tempo.

A educação não escolar começa a ser pensada e articulada a partir de uma série de críticas ao ensino institucionalizado, o que se traduziu na emergência de deslocamento na educação como sinônimo de escola. Compreender que o processo de aprender está colado em práticas de experimentação, as quais podem ser vivenciadas em outros espaços educativos, vai ao encontro da ideia de intervir em contextos diferenciados.

Dito isso, reiteramos que, ao legitimar a atuação do pedagogo nos espaços não escolares, a legislação nacional aponta a ampliação do campo de atuação da Pedagogia além das práticas docentes institucionalizadas. Entretanto, o que nos interessa neste texto é perceber como os saberes da Pedagogia vêm se constituindo progressivamente enquanto campo de conhecimento e, a partir da inserção, intervenção e realização das práticas dos acadêmicos no espaço não escolar, como esses mesmos saberes são registrados e posteriormente interrogados. Nesse sentido, compreendemos que a proposição de escrever no Diário de Campo contribui e interfere no processo formativo dos 
acadêmicos, uma vez que possibilita rever, repensar, retomar aspectos que mobilizam o pensamento, o qual, por sua vez, interroga o próprio currículo do Curso de Pedagogia e os modos como nos constituímos enquanto docentes.

\section{Referências}

BOCCO, Fernanda. Cartografias da Infração Juvenil. Porto Alegre: Abrapso Sul, 2009.

BRASIL, Conselho Nacional de Educação, Conselho Pleno. Resolução CNE/CP no.1, de 15 de maio de 2006.

BRASIL, Conselho Nacional de Educação, Conselho Pleno. Resolução CNE/CP no.2, de 01 de julho de 2015.

CORRÊA, Guilherme. Oficina: novos territórios em educação. In: PEY, Maria Oly (org.) Esboço para uma história da escolar no Brasil: algumas reflexões libertárias. Rio de Janeiro: Imaginário, 2000, p. 181-202.

CORRÊA, Guilherme Carlos; PREVE, Ana Maria Hoepers. A educação e a maquinaria escolar: produção de subjetividades, biopolíticas e fugas. Revista de Estudos Universitários, Sorocaba, v. 37, n. 2, p. 181-202, dez/2011.

CRIZEL, Ana Paula; HATTGE, Morgana Domênica. Dos processos e efeitos da escolarização em um espaço não escolar. In: MUNHOZ, Angelica Vier et. al. Anais do I Seminário Nacional Formação Pedagógica e Pensamento Nômade: experimentações curriculares. Lajeado: Editora Univates, 2015, p. 213-217.

FERREIRA, Aurélio Buarque de Holanda. Novo Dicionário Aurélio da Língua Portuguesa. 3ed. Curitiba: Positivo, 2004.

FOUCAULT, Michel. A arqueologia do saber. Rio de Janeiro: Forense Universitária, 2009.

GOHN, Maria da Glória. Educação não formal e o educador social: atuação no desenvolvimento de projetos sociais. São Paulo: Cortez, 2010.

GUATTARI, Félix. As três ecologias. Trad. Maria Cristina F. Bittencourt; revisão Suely Rolnik. 21ed. Campinas: Papirus, 2012.

KASTRUP, Virginia. O funcionamento da atenção no trabalho do cartógrafo. Psicologia \& Sociedade; 19(1): 15-22, jan/abr. 2007.

LARROSA, Jorge. Tremores: escritos sobre a experiência. Trad. Cristina Antu- 
nes e João Wanderley Geraldi. Belo Horizonte: Autêntica, 2014.

MUNHOZ, Angélica Vier. Práticas investigativas: experiências não escolarizadas. In: MUNHOZ, Angélica Vier (et al). Diálogos na Pedagogia: Coletâneas, v. 1 - Currículo. Lajeado: Univates, 2012.

OLEGÁRIO, Fabiane. Rastros das linhas menores de escrita. Dissertação (Mestrado em Educação). Programa de Pós-Graduação em Educação. Universidade de Santa Cruz do Sul, Santa Cruz do Sul, 2011.

ROLNIK, Suely. Cartografia Sentimental. Transformações contemporâneas do desejo. São Paulo: Estação Liberdade, 1989.

UNIVATES, Projeto Pedagógico do Curso de Pedagogia. Lajeado, 2017.

Data de recebimento: 22.08 .2020

Data de aceite: 23.12 .2020 